Studia Anglica Posnaniensia 45/1, 2009

(C) School of English, Adam Mickiewicz University, Poznań, Poland

doi: 10.2478/v10121-009-0005-6

\title{
LEXICAL CLASSES AND THE CONATIVE CONSTRUCTION IN OLD ENGLISH ${ }^{1}$
}

\author{
EULALia Sosa ACEVEDO
}

University of La Laguna

\begin{abstract}
This paper is concerned with the description of the event structure and the meaning components that motivate the realization of the conative construction within some canonical Old English verb classes. In the same line as the latest proposals framed within the Lexical Constructional Model, this kind of description is intended to evidence the essential role of semantic features that are not necessarily realized in the syntax and thus help elucidate and comprehend lexical-constructional processes. Besides, this work seeks to establish adequate criteria to identify the conative construction and provides insights into the distribution of diathetic alternations associated to the conative construction in Old English.
\end{abstract}

\section{Introduction}

Goldberg (1995: 63) defines the conative construction as " $x$ directs action at $y$ " which designates the intended result of the action, i.e. an action for which no accomplishment or result is expressed. The fact that no completion of the action is indicated by this construction becomes clear from the so-called "conative alternation" between the transitive and intransitive-prepositional patterns shown by some Present-day English verb classes, more specifically those that involve the notions of "motion" and "contact" (see Levin 1993: 41-42; Goldberg 1995: 63-64). Con-

1 Financial support for this study has come from two research projects entitled "Arquitectura semántica y catálogo de construcciones sintáctico-semánticas del ingles antiguo" (Ref: HUM2005-07651-02-1 C02-01) and "Construcción de una base de datos léxica y construccional inglés-español en el nivel de gramática nuclear" (Ref: ffi2008-05035-c02-02/filo), both funded by the Spanish Ministry of Science and Technology. 
sider, for instance, the following examples taken from Lee (2003: 171-173):

1) a. The visitors beat the door down.

$a^{\prime}$. ?? The visitors beat at the door down.

b. She pulled the tablecloth off.

$\mathrm{b}^{\prime}$. ?? She pulled at the tablecloth off.

c. ?? The player knocked the ball but missed.

$\mathrm{c}^{\prime}$. The player knocked at the ball but missed.

The locative particles down and off in (1a) and (1b) denote the final position or location of the object, i.e. a change of location as a result of the action of beating and pulling respectively. This kind of particles cannot occur when the prepositional at-phrase is introduced as in $\left(1 \mathrm{a}^{\prime}\right)$ and $\left(1 \mathrm{~b}^{\prime}\right)$ since both beat at and pull at denote intended actions with no specified result. Similarly, $\left(1 \mathrm{c}^{\prime}\right)$ indicates that no result is involved by knock at. Otherwise, the action could not be missed (see Quirk et. al. 1985: 697).

In what follows, we shall try to demonstrate that some Old English verbs classes such as the verbs of running and contact-by-impact verbs share the basic features of the conative construction as well as what we will label as the locative-conative alternation. In addition, we will contend that, in contrast to Levin's (1993) proposal, the conative construction is not restricted by transitivity. Information on diathesis alternations and on constructions will be used as a means to identify the relevant subevents and the participants involved in them, one of the principal advantages of this kind of analysis being that it accounts for the role of meaning components that are not necessarily expressed syntactically.

We will support our claims by presenting samples appropriately collected from, and examined in the context of, the following sources: A thesaurus of Old English (Roberts et al. 1995); Bosworth, Toller and Campbell's Anglo-Saxon dictionary (henceforward BT); A concise Anglo-Saxon dictionary (Hall [19601996] 1894); The Helsinki corpus of English texts (Rissanen et al. 1991) and The Oxford English dictionary (Murray et al. [1987] 1971, henceforward OED). ${ }^{2}$

\section{Contact-by-impact verbs}

One of the crucial features characterizing Old English contact-by-impact verbs concerns the syntactic realization of the instrument arguments as subjects. As illustrated in (2) below, this instrument-subject alternation (see Levin 1993: 80)

2 For further information on the methodology of corpus selection, we refer the reader to the following contributions published within the framework of the abovementioned research projects: Cortés and Mairal (2002), Cortés and Torres (2003), Cortés and Plaza (2006), and Sosa (2007). 
accounts for the fact that, in active voice expressions involving verbs like beátan (to beat), the instrument argument can be expressed either as an oblique case or as the subject of a clause. Thus, in (2a), the instrument (hameron) is realized by the instrumental case introduced by the preposition mid 'with'. This realization alternates with (2b) in which hamer is the subject of a clause (see Cortés - Plaza 2006: 85):

2) a. man mid ðám hameron Instr beóte on ðat isene pell. man-with-the-hammer Instr-beat-on-the-iron-plate 'The man beat at the iron plate with the hammer'

(Wulfst. 147, 2-7).

b. Hit anginne eal cetgidre brastligan, and ðá hameras ${ }_{\mathrm{Nom}}$ beátan... It-began-all-together-to brustle- and- the hammers-to beat 'It began all together to brustle, and the hammers to beat...'

(Sal. K. p. 85, 21).

Not all the instrument arguments, however, can be realized as subjects. This has been put forward clearly within Role and Reference Grammar (henceforward RRG) by proposing this syntactic restriction on subject realization as a means to distinguish "instruments" from "implements" with activity verbs (see Van Valin - LaPolla 1997: 121; 2005: 59). Expressions like (3) and (4) below are typically quoted as unambiguous instances justifying this restriction. As can be observed, only hammer in (3a) can be realized as subject and thus qualifies as instrument while spoon in (4a) acts as implement given that it cannot be expressed as the subject of an activity verb like to eat. ${ }^{3}$

3) a. The hammer broke the window.

b. John broke the window with a hammer.

4) a. Chris ate the soup with a spoon.

b. *The spoon ate the soup.

In overt parallelism with these examples, the Old English corpora contain numerous samples like (5) below in which the instrument argument (e.g. sticca 'spoon') is likewise interpreted as an implement rather than as an instrument since no instance of sticca occurring as the subject of activity verbs like hréran 'to stir' or etan 'to eat' has been identified:

3 This distinction is perhaps more clearly captured by Levin's (1993: 80) terminology: instruments are "intermediary instruments" and implements are "facilitating instruments". 
5) a. Hrér mid sticcan óp-ðœet hit cól sie. stir-with-spoon-till-it-cool-be 'stir it about with a spoon till it be cool'

(7.476 c: licameloehels $\sim 1 \backslash$ colaece 7; L. M. 3, 26;

Lchdm. ii. 324, 1: 2, 51).

b. Styre ðonne mid dy sticcan ða buteran .

stir- then- with-the-spoon-the-butter

'stir the butter with a spoon'

c. ...pú mid sticcan etan wile,

(2.871 c:licameloehels $\sim 1 \backslash$ colacnu 98).

... you-with-spoon-eat-want

'... you want to eat with spoon'

(Tech. ii. 123, 5).

Considering that this kind of evidence is provided by appropriate corpus selection, we will assume that Old English contact-by-impact verbs in expressions like (2a) are subject to the restriction on instrument-implement realization as well as to the following generalizations and constraints this restriction entails within RRG (see Van Valin - LaPolla 1997: 85, 107, 121; Van Valin 2005: 59):

6) i) Only instruments (as opposed to implements), which are part of a causal chain, may be realized as subjects.

ii) Only instruments can be effectors in the causal chain. Since instruments, by definition, are not capable of independent motion and action, they require the occurrence of another effector, i.e. a controller over the action that the instrument carries out. For instance, the man in (2a) above appears as an effector licensing the hammer to do something.

iii) The causal chain is complex in that the same entity (e.g. hammer) appears as both:

a. the implement argument in the causing event. Thus, in (2a), there is a user that manipulates the implement hammer.

b. the effector argument in the caused event. Thus, in (2a) the hammer is an instrument carrying out the action of beating.

Now, what is important about these generalizations is that they provide essential criteria to identify central subevents and participants relevant to Old English contact-by-impact verbs, namely, the existence of a causal event and, besides the role of the instrument and implement arguments, the involvement of 
two effectors (cf. Cortés - Plaza 2006: 93):

7) a. There is a first subevent $\left(\mathrm{e}_{1}\right)$ in which an effector makes use of an object in a specific way. This can be expressed as " $x$ uses $y$ in a manner", for example, the man uses the hammer in a manner.

b. There is a causative relationship between two subevents so that a CAUSING subevent $\left(\mathrm{e}_{1}\right)$ brings about a CAUSED subevent:

i) $\mathrm{e}_{1}$ (" $x$ uses $y$ in a manner") appears as a CAUSING subevent involving $x$ as effector and $y$ as implement.

ii) by virtue of (6 ii) above, the CAUSED subevent $\left(\mathrm{e}_{2}\right)$ takes this implement $y$ as an effector, i.e. as the doer of an action and hence " $y$ does something".

c. The full causal event can be expressed as:

" $x$ uses $y$ in a manner which CAUSES $y$ to do something".

It should be observed that, though the instrument-subject alternation helps us state that there is an action " $y$ does something" (e.g. the hammer beats the plates) associated to the CAUSED subevent $\mathrm{e}_{2}$, it does not tell us much about what this action exactly denotes. In other words, what does the action of beating or striking someone or something really designate?

Let us begin by considering the following sample:

8) ... ða cwelleras mid stearcum ságlum hine beóton.

... the-executioners-with-hard-sticks-him-beat

'The executioners beat him with hard sticks'

(Homl. Th. i. 424, 32).

On first inspection, it seems intuitively reasonable to argue that "beating him" requires, first, the executioners to move the sticks towards the object "him", and second, the sticks to enter into physical contact with "him". Even though these properties are not expressed syntactically, we intend to demonstrate that contact-by-impact verbs invariably comprehend these features as inherent semantic components and that, as such, they should be part of their event description.

Strong evidence suggesting that such factors are indeed essential semantic aspects of the instrumental construction is provided by careful analysis of another relevant alternation cutting across this verb class: corpus selection indicates that verbs like beátan 'to beat' or cnucian/cnocian 'to knock' participate in the so-called transitive-conative alternation. From a syntactic perspective, this means that these verbs may alternatively take a direct object in the accusative case, as in (9a) and (10a), or a prepositional object introduced by on (occa- 
sionally by $a t$ ) followed by accusative case objects as in (9b) and (10b):

9) a. He beót his breost $_{\mathrm{Acc}}$ and cwop...

he-beat-his-breast-and-said

'He beat his breast and said'

b. He on his breóst $t_{\mathrm{Acc}}$ beót.

(Lk. Bos. 18, 13).

He-on-his-breast-beat

'He beat on his breast'

(H. R. 15, 29).

10) a. Stormas stánclifu $u_{\mathrm{Acc}}$ beótan

storms- rocks-beat

'The storms beat the rocks'

b. Scé on staðu beátep

(Th. 307, 13; Seef. 23).

sea-on-shore-lashes

'The sea lashes against the shore'

(Bt. Met. Fox 6, 30; Met. 6, 15).

As with the instrument-subject alternation, the occurrence of the transitiveconative alternation brings in definite implications for the semantic characterization of these verbs, the most important being that this alternation requires verbs denoting motion and contact. In Levin's more precise words, contact-byimpact verbs "describe moving one entity in order to bring it into contact with another entity" (Levin 1993: 10).

In order to appropriately account for both motion and contact as essential semantic properties motivating the interpretation of this verb class, we propose to reformulate the full event structure presented in $(7 \mathrm{c})$ above in the following lines:

11) an effector $x$ uses an object $y$ in a manner so that this causes $y$ move towards an object $z$ with which $y$ enters into contact.

To illustrate the complete realization of the event, consider the interpretation of sample (12) below: the effector/mover (he) moves his hands (his handum) in a manner so that this causes his hands move towards and contact someone (hine).

12)

... doet he hine mid his handum hetelice beot.

... so that-he-him-with his hands-furiously-beat

'... so that he beat him furiously with his hands'

(c:licameloehels $\sim 1 \backslash \operatorname{cogregd} 3$ 17). 
The description we propose in (11) provides a more straightforward account of the CAUSED subevent (" $y$ does something") which appears to be complex in that it can be decomposed into two subevents: "motion" expressed as " $y$ moves towards $z$ ", and hence "location-plus-contact" expressed as " $y$ touches $z$ ".

This allows us to express in more detail the component subevents initially described in (7) above:

13) a. The first subevent $\left(\mathrm{e}_{1}\right)$ denotes that an effector uses an object (implement) in a manner. This is expressed as " $x$ uses $y$ in a manner", where $x$ is an effector and $y$ an implement.

b. There is a causal chain in which the subevent $e_{1}$, the CAUSING subevent (" $x$ uses $y$ in a manner"), brings about a complex CAUSED subevent " $y$ does something" whereby $y$ becomes an instrument.

c. The CAUSED subevent thus comprises two other subevents:

i) first, a subevent of "motion" $\mathrm{e}_{2}$ denoting that "instrument $y$ moves towards $z$ "

ii) second, a subevent of "location-plus-contact" $e_{3}$ denoting that "instrument $y$ touches $z$ ".

On the basis of these data, we can now claim that samples showing the transitive realization like (14a) and (15a) below in which the implement/instrument is not syntactically realized, are nevertheless interpreted as denoting an activity in which an effector (Balaam, ge) uses an object $(y)$ - syntactically unspecified here - which causes this object $(y)$ to move towards an object ( $z$ ) (the ass, the door) that receives the contact/impact (i.e. " $y$ touches the ass/ the door"):

14) a. Balaam beot ðone assan Acc. $_{\text {. }}$

Balaam-beat-the-ass

'Balaam beat the ass'

b. Sć on staðu beáteb

(Num. 22, 23).

sea-on-shore-lashes

'The sea lashes against the shore'

(Bt. Met. Fox 6, 30; Met. 6, 15).

4 Following Wierzbicka (1996), we use the word "touch" to indicate spatial support and surface. Mairal and Cortés (in press) likewise incorporate Wierzbicka's semantic primitive touching to the qualia structures representating "contiguous location" in contact-by-impact verbs. 
15) a. ... and (ge) pa duru $\mathrm{Ac}_{\mathrm{Ac}}$ cnuciað and cweðap.... ... and-(you)-the door-knock-and-say

'... and (you) knock the door and say...'

(Lk. Skt. 13, 25).

b. Heó on pcere cýtan duru $\mathrm{Ac}_{\mathrm{Ac}}$ cnocode. she-on-the-hut-door-knocked

'She knocked at the door of the hut'

(Hml. A. 196, 26).

As for the prepositional samples (14b) and (15b), they denote the same kind of activity. However, a substantial difference with the transitive expressions is that the prepositional patterns seem to convey conative meaning. This can be justified on both semantic and syntactic grounds. On the one hand, contact-byimpact verbs, as we have made clear elsewhere, satisfy the precondition of denoting motion and contact (see Goldberg 1995: 63). On the other hand, the conative construction is realized by a prepositional phrase introduced by on preceding accusative case objects. The $B T$ accounts for this use of on as "marking motion, actual or figurative, which is external to the object expressed by the word which on governs [and] introduces the object in relation to which an action takes place" (v.s. on).

Notice that no consummation of the action is inferred from this description of the preposition on with the accusative case. Actually, it does not necessarily imply contact with the object it introduces but rather delimits the direction towards which the action of moving is intended, i.e. unlike (14a) and (15a) which denote fully-obtained, telic actions, expressions like (14b) and (15b) are interpreted as "the sea moves towards the shore in an attempt to contact the shore she moves (her hand) towards the door in an attempt to contact the door", but actual "contact" remains unspecified.

One point that deserves mention at this stage is that this interpretation converges with one of the uses of Present-day English at when accompanying verbs like shoot. In this context, at indicates "the intended goal or target, where there is no attainment of the goal" (Quirk et al. 1985: 697). In contrast, the Old English preposition ot typically introduces the dative case and "expresses the position reached by completed motion to" (see $O E D$ v.s. $a t$ ), "the point at which, object by or in contact with which something is placed" (see $B T$ v.s. $c t$ ). As an instance, consider the following samples: ${ }^{5}$

5 Not uncommonly, these expressions denote hostility and the preposition is usually translated as 'against' as in (16b) (see Quirk et al. 1985: 697; Levin 1993: 148). 
16) a. ... ðcet his fót cet stáne $e_{\text {Dat }}$ ópspurne.

... that-his-foot-at-stone-strikes

'... that his foot strike against/on a stone'

(Bl. H. 29, 31).

b. ... cet ðœem uferran ende $e_{\text {Dat }}$ Dryhten hlinode.

... at-the-highest-position-Lord-rested

'... at the highest position the Lord rested'

(Past. 101, 19).

As can be seen, regardless of whether the verb denotes motion as ópspurne in (16a) or state as hlinode in (16b), the prepositional phrases cet stáne and cet ðcem uferran ende pinpoint the location against which the foot (fót) moves and the Lord (Dryhten) is placed at respectively.

Going back now to the conative realization of contact-by-impact verbs, we observe that this semantic contrast between on and cet appears to be systematic across samples properly drawn from the corpus, which indicates the existence of a locative-conative alternation. Compare, for instance, the following samples:

17) a. He cnucode cet ðcere dura $a_{\text {Dat. }}$ he-knocked-on-the-door

'He knocked on the door'

(Homl. Th. ii. 382, 17, 22).

b. Heó on pare cýtan duru $u_{\mathrm{Ac}}$ cnocode.

she-on-the-hut-door-knocked

'She knocked at the door of the hut'

(Hml.A. 196, 26).

While the cet-complement in (17a) designates the position reached by, for instance, the effector's hand, and thus it encodes the locative construction, i.e. actual contact with a location (duru 'door'), the on-complement in (17b) licenses the conative construction, i.e. motion intented to contact the door (duru) which may or may not be accomplished.

Finally, in terms of event structure, the locative-conative alternation can be accounted for by interpreting the CAUSED subevent in two alternating ways: the conative construction encodes the CAUSED subevent given in (13c) above (here repeated in (18c.i) while the locative construction only incorporates a locative subevent as expressed in (18c.ii) below. The full event structure can thus be restated as follows: 
18) a. The first subevent $\left(\mathrm{e}_{1}\right)$ denotes that an effector uses an object (implement) in a manner. This is expressed as " $x$ uses $y$ in a manner", where $x$ is an effector and $y$ an implement.

b. There is a causal chain in which the subevent $e_{1}$, the CAUSING subevent (" $x$ uses $y$ in a manner"), brings about a complex CAUSED subevent " $y$ does something" whereby $y$ becomes an instrument.

c. The CAUSED subevent may be alternatively realized as encoding:

i) either the conative construction which comprises two subevents:

- first, a subevent of "motion" $\mathrm{e}_{2}$ denoting that "instrument $y$ moves towards $z "$

- second, a subevent of "location-plus-contact" $e_{3}$ denoting that "instrument $y$ touches $z$ ".

ii) or the locative construction that denotes a single subevent of "location" $\mathrm{e}_{2}$ expressing that " $y$ is at $z$ "

Notice that this description evidences that what marks the distinction between the conative and the locative constructions is basically the presence or absence of a subevent of "motion".

In concluding this section, and for the sake of clarity, we summarize below the major constructions and alternation patterns thus far identified within the class of contact-by-impact verbs:

19) i) instrument-subject alternation: in the instrumental construction, the instrument argument appears as subject.

ii) transitive-conative alternation: in the transitive construction, the object takes the accusative case; in the conative construction, the accusative case object is introduced by preposition on.

iii) locative-conative alternation: in the locative construction, the object is realized prepositional phrases introduced by $x e t$ followed by dative case while, in the conative construction, the accusative case object is preceded by the preposition on.

\section{Run verbs}

The alternation between activity and active accomplishment realizations is a basic characteristic of Present-day English verbs of motion like run which show aspectual differences of "telicity", i.e. whether a given activity is terminated 
[+telic] or has a dynamic, non-terminal interpretation [-telic] (see Van Valin 2005: 33-34). For instance, (20a) below designates an activity since there is no indication that the horses stop running at any temporal/spatial stage. In contrast, (20b) designates an active accomplishment since the horses are judged to stop running once they arrive at the woods:

20) a. The horses ran in the woods

b. The horses ran to the woods

Cortés and Torres (2003: 163) observe the same kind of alternation between intransitive and intransitive-locative uses of prototypical Old English verbs of running like yrnan, reesan and raccian. The following samples exemplify this alternation:

\section{1) ACTIVITY}

a. Đá arn dcet wif swìe

Then-ran-the-woman-fast

'Then the woman ran fast'

b. Đū urne mid him

you-ran-with-him

'You ran with him'

(Homl. Skt. i. 3).

(Ps.Th. 49,19).

c. Đá arn hé and gestód ongeán ðam lége.

then-ran-he-and-stood-opposite-the-flame

'Then he ran and stood opposite the flame'

(Bl. H. 221, 11).

\section{2) ACTIVE ACCOMPLISHMENT}

a. Hé résde intó ðam wudu $u_{\mathrm{DAT}}$. he-rushed-into-the-woods

'He rushed into the woods'

b. Sume urnon intó cyrcean $n_{\mathrm{DAT}}$

some-ran-into-church

'Some ran into the church'

(Homl. Skt. ii. 30, 31).

(Chr. 1082; Erl. 217, 13). 
c. Đonne orn hē eft inn tō ðcem temple $e_{\mathrm{DAT}}$ then-run-he-again-in-to-the-temple 'Then he ran again into the temple'

(Past. 16, 3).

d. ... paet hé tó hrcedlice intó Godes húse $e_{\text {Dat }}$ racige. ... that-he-to-soon-into-God-house-ran

'... that he soon ran into God's house'

(Wlfst. 155, 16-21).

e. Aaron ða ardlice arn to ðam folce Dat $_{\text {and }}$ sterde mid thimiama Aaron-quickly-ran-to-the-people-and-burnt-with-incense 'Aaron ran to the people and burnt with incense'

(6.515 c: licameloehels $\sim 1 \backslash$ cootest 64$)$.

The $O E D$ and the $B T$ describe both tó and intó as regularly introducing dative case objects (see $B T$ s.v. tó, intó). In addition, these sources specify that, with motion verbs, tó designates location after motion, i.e. the end reached by that which moves to or at (e.g. reaching the temple in 22c). Similarly, intó is defined as denoting location in space attained through motion, i.e. motion to a position within a space or thing (e.g. going in the church in 22b). Thus, like Present-day verbs of running, Old English run-verbs mark telicity by means of a prepositional complement designating completion of the activity, the endpoint of the action of motion, which triggers an active accomplishment realization of the verb. Conversely, the absence of completion of the action correlates with the dynamic interpretation corresponding to activity events. This is exemplified in (21) above: the adverbs and the prepositional phrases (fast, with him) indicate the manner in which the activity of running takes place but no explicit expression of a final location for motion is encoded.

Let us now make an attempt to describe the event structure associated to this alternation:

23) a. The intransitive activity realizations illustrated in (21) denote an event of "motion" $\left(\mathrm{e}_{1}\right)$ in which a type of effector, the mover $x$, moves quickly in a manner (e.g. fast). This is expressed as " $x$ moves quickly in a manner" (e.g. "the woman runs/moves fast").

b. The active accomplishment realization designates the terminal point of the event of motion $\left(\mathrm{e}_{1}\right)$, this information being provided, as we have shown, by a locative/directional prepositional phrase. This leads us to 
consider that this event comprises two subevents:

i) the "motion" subevent ( $\mathrm{e}_{1}$ : " $x$ moves in a manner")

ii) the complementing "locative" subevent designating " $x$ is at $y$ ", i.e. " $x$ is at the terminal spatial point/location $y$ ".

At this point it is necessary to address an important question. Cortés and Torres (2003: 164) suggest that activities can be expressed as " $x$ moves quickly in a manner towards $\alpha$ ", where $\alpha$ is an internal variable indicating that, as we claimed above, the syntactic realization of this kind of constructions does not explicitly indicate "a terminal endpoint to the moving action" (Cortés - Torres 2003: 163). As for the active accomplishment uses of these Old English verbs they propose, in the same vein as RRG (see Van Valin - LaPolla 1997: 111, 152), two complementing subevents: $\mathrm{e}_{1}$ : " $x$ moves quickly in a manner toward $\alpha$ " and $\mathrm{e}_{2}$ : " $x$ becomes be at the location $z$ ", where $\alpha$ is realized as $z$, i.e. the location, the terminal point, is syntactically expressed. This is more clearly seen in the templates they formulate to represent each of these constructions (Cortés - Torres 2003: 164):

24) a. Activity Lexical template [do' (x, [move.quickly.in.a.manner.toward. $\left.\left.(\alpha)^{\prime}(\mathrm{x}, \varnothing)\right]\right)$

b. Active accomplishment template:

[do' (x, [move.quickly.in.a.manner.toward. $\left.\left.(\alpha)^{\prime}(\mathrm{x}, \varnothing)\right]\right) \&$ BECOME be$\left.\operatorname{LOC}^{\prime}(\mathrm{z}, \mathrm{x})\right]$

It should be observed that the activity template encodes directionality expressed by toward. $(\alpha)$. However, this interpretation does not seem to conform to activity realizations like "the woman ran fast" in (21a) which denote no specific direction towards which the woman runs. Observe that this is precisely the case in Old English: though it is true that the samples in (21) denote displacement, change of location of a moving object, they do not specify directionality or goal by any means. In contrast, the samples in (22) express the goal or location of/for motion, i.e. the mover moves up to the woods, the church, the temple, the house, etc. (cf. Cortés - Torres 2003: 164-165). Actually, direction is likewise absent from expressions including in-phrases. As we explained above, in the woods, in sentences like the horses ran in the woods, does not mark telicity, nor does it encode directionality since what this phrase designates is the spatial setting within which the action of running takes place in a dynamic way rather than the direction towards which the horses run (see Van Valin 2005: 49). Interestingly, the same interpretation holds for Old English run-verbs when followed by prepositions marking space. Thus, in (25) below, embe poer (around a place) 
denotes neither termination of, nor direction for, the action of running:

25) hors urnon embe poer.

horses-ran-around-there

'Horses ran around there'

(Hml. S. 27, 39).

In our view, therefore, as Levin (1993: 106) claims, verbs like run are manner-of-motion verbs which only denote directionality or goal of motion when they occur with directional/goal phrases. This is, actually, a cross-linguistic phenomenon (see Van Valin - LaPolla 1997: 99). In view of these facts we propose to reformulate the constructions involved in the intransitive-locative alternation as follows (cf. Cortés - Torres 2003):

26) a. the intransitive construction exemplified in (21) is expressed as " $x$ moves quickly in a manner"

b. the locative/directional construction illustrated in (22) designates that " $x$ moves quickly in a manner towards y and becomes be at $y$ "

We can now express the component subevents as follows:

27) a. Activity realizations (i.e. intransitive constructions) denote an event of "motion" $\left(\mathrm{e}_{1}\right)$ : " $x$ moves quickly in a manner"

b. Active accomplishment realizations denote a "directional/locative" event comprising two subevents:

i) first, a subevent of "direction" $\left(\mathrm{e}_{2}\right)$ denoting that " $x$ moves towards $y$ "

ii) second, a subevent of "location" $\left(\mathrm{e}_{3}\right)$ denoting that " $x$ is at $y$ "

It must be emphasized that the subevent description presented in (27b) is directly motivated by the definitions and case assignment quoted from the $B T$ (sv. tó) and the $O E D$ (s.v. to) in which tó encodes the notion of "location after motion" and intó the directional/locative meaning "motion towards a location".

Altogether, what the Activity/Active accomplishment alternation in fact subsumes in an intransitive/directional-plus-locative alternation. For the sake of clarity, however, we will still use henceforward the simplified label "intransitive-locative alternation".

Our analysis of the basic corpus indicates that, besides prepositional complementation with tó and intó, Old English verbs of running take complementation patterns with the preposition on followed either by accusative case (with conative meaning) or by dative case objects (with locative meaning). Comparison of samples like those given below reveals that the complementation pattern on+accusative object, i.e. the conative construction, alternates with the locative construction in much the same way it does within the class of contact-by-impact 
verbs (cf. Section 3.1):

28) a. ... paet hé tó hrcedlice intó Godes húse $e_{\text {Dat }}$ racige.

... that-he-to-soon-into-God-house-ran

'... that he soon ran into God's house'

(Wlfst. 155, 16-21).

a'. Arn hé sóna on pót hús $\mathrm{ACC}_{\text {. }}$

rushed-he-soon-on-the-house

'He soon rushed on the house'

(Bl. H. 221, 11).

b. ... and (hé) rósde tó ðám were $e_{\text {Dat }}$

... and-(he)-rushed-to-the-man

'... and he rushed to the man'

(Hml. S. 25, 225.).

b'. Hē, getogene dy wapne, raesde on ðone cyning Acc he- bringing-the-weapon- rushed-against/on-the-king 'He, bringing the weapon, rushed against/on the king'

$(\mathrm{Bd}, 2,9)$.

Observe that the locative prepositions introducing dative objects in (28a) and (28b) alternate with the preposition on followed by the accusative case in (28a') and $\left(28 b^{\prime}\right)$, the latter being associated to the conative construction by applying the same kind of rationale we propounded in Section 2.

On the whole, from the preceding discussion we conclude that the class of Old English run-verbs shows at least two basic alternations:

29) a. the intransitive-locative alternation

b. the locative-conative alternation

\section{Reconsidering criteria for the conative construction}

In this section we address some essential issues regarding the interpretation of the conative alternation as a transitivity alternation (Levin 1993: 41).

First, it should be noted that the alternations associated to contact-by-impact verbs in (19) and to run-verbs in (29) differ in that the latter do not show any transitive-conative alternation. However, in the strict sense, Levin defines the conative construction as derived from transitive verbs by introducing prepositional phrases. The fact that run-verbs are intransitive might therefore appear as a handicap for our proposal of a conative construction within this verb class. Actually, this mismatch with respect to transitivity has led Cortés and Torres (2003: 165) to use the label "pseudo-conative" construction when the alterna- 
tion takes place with intransitive verbs.

We contend, however, that the analysis we have carried out here proves appropriate and sufficiently demonstrates that the alternation of specific prepositions (tó, intó and $a t$ heading dative objects versus the pattern of on introducing accusative case) emphatically indicates that the conative construction may occur in alternation with the locative construction regardless of whether the Old English verb is transitive, like contact-by-impact verbs, or intransitive like run-verbs.

A second crucial aspect that deserves close attention has to do with whether the verb run is a motion-contact verb or not.

Recall that, like Goldberg (1995: 63-64) and Levin (1993: 41-42), we have assumed that the conative construction is only triggered by verbs that denote motion and contact. Levin (1993: 8-9), however, following Guerssel et. al. (1985), claims that prepositional expressions such as move at or run at denote pure motion, but not contact, which leads her to consider that these forms do not qualify as instances of the conative construction proper. The core argument of this claim, as she argues, lies in the fact that transitive expressions like Jean moved the table cannot be derived from the corresponding complementation expression Jean moved at the table by dropping of the preposition at (Levin 1993: 8) and, therefore, Jean moved at the table does not convey the conative meaning 'Jean attempted to move the table'.

Our view is that this line of reasoning shows important weaknesses.

To begin with, one can argue that Jean moved the table, being a transitive construction, has a causative activity interpretation, i.e. 'Jean causes the table to move' rather than a pure Activity reading as in the intransitive constructions like, for instance, Jean moved gently. As Van Valin and LaPolla (1997: 100101, 111) indicate, Active accomplishments are defined as the accomplishment uses of Activity predicates, and motion active accomplishments are not causative. Similarly, in her treatment of the conative construction, Goldberg emphasizes that it permits exceptions to the Causal Relation Hypothesis (Goldberg 1995: 62-63; Croft 1991:160), i.e. the conative construction does not denote causally related events. These restrictions thus prevent any alternation between causative activity realizations like Jean moved the table and Active Accomplishment (locative) expressions like Jean moved at the table. Since, as it will become clear from our discussion below, the conative construction with both Present-day and Old English motion verbs like run occurs in alternation with the locative construction, it is the locative Jean moved to the table, in that case, which alternates with the conative Jean moved at the table. Besides, notice that, in fact, the kind of alternation that expressions like Jean moved the table could be involved in is the Induced Action Alternation which Levin (1993: 31) identifies as a type of causative alternation.

As we stated at the beginning of section 3, the basic alternation characteriz- 
ing motion verbs is that between Activity (intransitive) and Active Accomplishment (directional/locative prepositional) realizations of these verbs. Just to illustrate this in more detail, consider the following samples extracted from the $B N C$. They show intransitive and locative constructions of both move and run which, as with Old English run-verbs, point clearly to the occurrence of the intransitive (Activity)/Locative (Active accomplishment) alternation with both verbs. Actually, the uses of Old English in, tó and intó totally correspond to Present-day English uses of in, to and into within this verb class.

\section{0) INTRANSITIVE CONSTRUCTION}

He moved in the jerky fashion of Jerry Lewis.

... they ran in unison.

(16.545c: \bnclflfp \fpa 33).

(11.104 c: :bnclb \bn\bnu 25).

\section{LOCATIVE CONSTRUCTION}

Maria moved at once to her mother.

(34.126 c: Ibnclalatlate 70$)$.

He ran to the door in his nightshirt, raising the alarm.

(2.761 c: \bnclalan\ank 7).

One last question that remains in relation to the status of move at and run at is why Levin interprets Jean moved at the table by paraphrasing it as 'Jean attempted to move the table' instead of 'Jean moved and attempted to be at the table'.

Though analysing in detail the uses of at-complementation with Present-day English motion verbs falls outside the scope of this paper, we have extracted from the $B N C$ numerous samples exemplifying the locative and the conative constructions with both move and run:

\section{1) LOCATIVE CONSTRUCTION}

a. Weeks ago our little kitten ran into the wood.

(32.650c: $\backslash b n c l b \backslash b 0 \backslash b 0 b 68)$.

b. ... he moved to the crock-filled sink, leaning on it compressing his lips

(19.297 c: Ibncla\a7\a7338).

\section{CONATIVE CONSTRUCTION}

a. The curtains moved at the window. 
(31.426 c: \bnclfffrlfrc 62).

b. He ran at the stairs, taking them three at a time

(18.556 c: \bnclclcm lcmp 38).

As we have explained and demonstrated previously in our discussion of Old English run-verbs, active accomplishment realizations that denote the locative construction, in their turn, alternate with the conative construction. It is not difficult to realize that the samples in (31) comply with the criteria we have raised elsewhere in this paper to demonstrate the occurrence of this locative/conative alternation. We thus argue that Present-day English and Old English run-verbs show the same kind of alternations, namely, the intransitive/locative alternation and the locative/conative alternation, and that, on this basis, Jean moved at the table should be interpreted as a conative construction: "Jean moved and attempted to be at the table".

In connection with this, we also claim that the decomposition into subevents represented in (27) above, particularly (27b ii), evidences why run, defined by Levin (1995: 8) as a "motion" but not as a "contact" verb, can possibly be realized with conative meaning: the subevent of location entails contact with the spatial endpoint of the activity. This can be rationalized from a cognitive perspective by claiming that the locative subevent metonymically entails experiential information such that a locatum being at a spatial location is necessarily in physical contact with that location, i.e. the locative subevent designates that "the mover $x$ reaches and physically contacts a given location or terminal point".

This kind of external explanation has proved suitable in describing some of the constraints that regulate processes of lexical-constructional subsumption within the Lexical Constructional Model (see Ruiz de Mendoza - Mairal, 2006a, 2006b). However, besides this kind of inferential cognitive argumentation, the fact that "contact" becomes part of the semantic makeup of run-verbs in active accomplishment realizations can be appropriately justified by applying more theory-internal criteria.

Consider the event structure described in (27), repeated below:

32) a. Activity realizations (i.e. intransitive constructions) denote an event of "motion" $\left(\mathrm{e}_{1}\right)$ : " $x$ moves quickly in a manner"

b. Active accomplishment realizations denote a "directional/locative" event comprising two subevents:

i) first, a subevent of "direction" $\left(\mathrm{e}_{2}\right)$ denoting that " $x$ moves towards $y$ "

ii) second, a subevent of "location-plus-contact" $\left(\mathrm{e}_{3}\right)$ denoting that " $x$ is at $y^{\prime \prime}$

Observe that "contact" is associated to the event structure of active accom- 
plishment realizations. Recall also that, in agreement with Levin, we have assumed that directionality/location, far from being an inherent property of runverbs, is only provided when directional/local prepositional objects co-occur with these verbs. It follows from these considerations that the notion of "contact" is incorporated to the meaning of run by means of specific prepositional complementation: $t o ́$ + dative objects in Old English; complementation with to in Present-day English.

Now, some important conclusions can be drawn at this point.

First, with the intransitive (uses of) verbs like run-verbs, it is the prepositions that contribute the semantics of "location/contact". On the contrary, with transitive (uses of) verbs, like contact-by-impact, "location/contact" is licensed by the object (E.g. ठone assan, 'the ass', in 14a above). It seems worthwhile to point out that the crucial role of prepositions in some constructions has been described within other functionally-oriented models and theories such as RRG or Pustejovsky's (1995) theory of qualia structure. In RRG, these prepositions are considered to be "predicative", and hence contribute meaning (directionality, location) to both the prepositional phrases and the clauses in which they occur (see Van Valin 2005: 21). In a similar way, Pustejovsky considers "directional PPs act as functions over the verb to give rise to a derivative verb sense ...".

Second, in view of the alternations that characterize these verb classes, expressed in (19) and (29) above, we conclude that the conative construction is not determined by transitivity as Levin proposes, since it alternates both with transitive and (intransitive)-locative constructions.

What is then the motivating factor underlying this construction?

Going back to the Activity/Active Accomplishment distinction, we realize that what the semantic components "location/contact" actually provide in the case of run-verbs is aspectual information on telicity introduced by means of the prepositional phrases. Recall that, for instance, in The horses ran to the woods, to the woods provides the end-point for the action of running, hence the "destination" (see Quirk et. al. 1985: 675; Van Valin 2005: 44). On the contrary, as expressed in (11), location/contact are inherent semantic components of contact-by-impact verbs, and so is telicity in their transitive, as oppossed to conative, realization. As Mairal and Ruiz de Mendoza (in press) indicate: “... 'hit' verbs are in essence verbs of contact and as such they integrate as a final subevent in their logical structure a stative contiguous - and not a result - location event". For instance, in (9a) above, He beót his breost: "he beat his breast", the end-point for the action of beating is guaranteed by the presence of the object breost ('breast') which represents the caused location.

All this leads to the important overall conclusion that the conative construction is sensitive to telicity in as much as it alternates with telic constructions, either transitive or intransitive (locative), which integrate the semantic compo- 
nents of "motion" and "contact".

As for the semantics of the conative construction, we can be quite precise: in the alternations with the transitive and the locative constructions discussed above, both marked for telicity, the conative construction seems to "downgrade" the prominence of telicity and convey some degree of uncertainty about the accomplishment of the action expressed by the verb.

We have emphasised elsewhere above that the conative construction provides no indication as to whether the action expressed by the verb is accomplished or not. In terms of event structure, this means that the conative construction does not inform us about whether the subevent of location/contact, specified in (33ii) below, is actually realized or not. Observe that, for instance, in the examples in (31) (The curtains moved at the window; He ran at the stairs) all we are certain is that both the curtains and he move towards the window and the stairs (i.e. there is actual motion of these subjects) and that, as a consequence, there could be some contact between these subjects and the window and the stairs respectively. However, nothing indicates that they actually "touch" the window and the stairs.

33) the conative construction comprises two subevents:

i) Actual Motion $\left(\mathrm{e}_{1}\right)$ : " $x$ moves towards $y$ "

ii) Intended Location/Contact: Intended Destination $\left(\mathrm{e}_{2}\right)$ : " $y$ touches $z$ ".

\section{Conclusion}

In this paper we have presented fundamental criteria and evidence indicating that the conative construction cross-occurs with both transitive and intransitive constructions. As regards intransitive uses, the conative construction seems to hold systematic diathetic alternations with the locative construction.

Close examination of corpus data has led us to some important conclusions.

First, "contact", one of the basic prerequisites for the conative construction, is not necessarily provided by the inherent semantics of the verb, as Levin and Golberg claim. Quite contrarily, the occurrence of the conative construction seems to depend directly on the presence or absence of aspectual information related to telicity, regardless of whether the verb (or its realization) is transitive or intransitive.

Second, both within the class of contact-by-impact verbs and of motion verbs, the conative construction is licensed by the presence of telicity (i.e. an endpoint for the action) via location/contact (destination). The difference lies only in the fact that the destination is part of the transitive construction with contact-by-impact verbs, whereas in the case of motion verbs, the destination is provided by means of directional/locative phrases that the locative construction incorporates. In either case, the conative construction modifies the interpretation of telicity by conveying uncertainty about whether the action designated by the 
verb has been terminated or not.

Finally, the analysis propounded in this paper suggests that the conative construction occupies a more privileged position within the scope of verb classes, both in Old English and in Present-day English, than it has been granted in previous accounts such as Levin's.

\section{REFERENCES}

Bosworth, Joseph - Thomas Northcote Toller

[1973]

1898 An Anglo-Saxon dictionary. London: Oxford University Press.

Cortés, Francisco José - Ricardo Mairal Usón

2002 "A preliminary design for a syntactic dictionary of Old English on semantic principles", in: Javier Díaz Vera. (ed.), 3-46.

Cortés, Francisco José - Francisca del Mar Plaza Picón

2006 "Los verbos de contacto-por-impacto en latín e inglés antiguo: semántica y motivación de estructuras morfo-sintagmáticas", in: Actes de VII Congrés de Lingüistica General. Publicacions i Edicions: Universitat de Barcelona. CD-Rom publication. ISBN: 84-475-2086-8.

Cortés, Francisco José - Dolores Torres Medina

2003 "Old English verbs-of-running: Linking semantic representation and morphosyntactic structure", Folia Linguistica Historica 24/1-2: 153-174.

Croft, William

1991 Syntactic categories and grammatical relations: The cognitive organization of information. Chicago: University of Chicago Press.

Díaz Vera, Javier E. (ed.)

2002 A changing world of words: Studies in English historical lexicography, lexicology and semantics. Amsterdam: Rodopi.

Goldberg, Adele

1995 A construction grammar approach to argument structure. Chicago: University of Chicago.

Guerssel, Mohamed - Kenneth Hale - Mary Laughren - Beth Levin - Josie White Eagle

1985 "A cross-linguistic study of transitivity alternations". Papers from the Parasession on Causatives and Agentivity. Chicago Linguistic Society: 48-63.

Hall, John R. Clark

[1960-1996]

1894 A concise Anglo-Saxon dictionary. Toronto - Buffalo - London: University of Toronto.

Lee, Keedong

2003 "The Conative Construction in English", Discourse and Cognition 10/3: 165-186.

Levin, Beth

1993 English verb classes and alternations. Chicago: University of Chicago Press.

Mairal Usón, Ricardo - Francisco José Ruiz de Mendoza Ibáñez.

in press "New challenges for lexical representation within the lexical-constructional model", 
Grammar, Constructions and Interfaces. Revista Canaria de Estudios Ingleses 57.

Murray, James A. H. et al. (eds.)

1971 The Oxford English Dictionary (compact edition, vols. 1, 2.) Oxford: Clarendon Press.

Pustejovsky, James

1995 The generative lexicon. Cambridge: MIT Press.

Quirk Randolph - Sidney Greenbaum - Geoffrey Leech - Jan Svartvik

1985 A comprehensive grammar of the English language. London - New York: Longman.

Rissanen, Matti - Ossi Ihalainen (eds.)

1991 Helsinki corpus of English texts: Diachronic and dialectal. Helsinki: University of Helsinki.

Roberts, Jane - Christian Kay - Lynne Grundy

1995 A thesaurus of Old English. vols. 1-2. London: King's College Centre for Late Antique and Medieval Studies.

Ruiz de Mendoza Ibáñez, Francisco José - Ricardo Mairal Usón

2006a "Internal and external constraints in meaning construction: The lexicon-grammar continuum", in: Estudios de Filología Inglesa: Homenaje a la Dra. Asunción Alba Pelayo [Available at: http://www.lexicom.es/drupal/files/constraints.pdf]

$2006 \mathrm{~b}$ "Levels of semantic representation: Where lexicon and grammar meet", Interlingüística 17: 26-47.

Sosa Acevedo, Eulalia

2007 "The semantic representation of Anglo-Saxon (ge-)séon and (gé)lócian: Syntactic evidence for meaning decomposition", Revista Electrónica de Lingüistica Aplicada 6: 92-107.

Van Valin, Robert D. - Randy LaPolla

1997 Syntax: Structure, meaning and function. Cambridge: Cambridge University Press. Van Valin, Robert D.

2005 Exploring the syntax-semantics interface. Cambridge: Cambridge University Press.

Wierzbicka, Anna

1996 Semantics: Primes and universals. Oxford: Oxford University Press. 